Article

\title{
Loss of AMPKalpha1 Triggers Centrosome Amplification via PLK4 Upregulation in Mouse Embryonic Fibroblasts
}

\author{
Qiang Zhao ${ }^{1}$, Kathleen A Coughlan ${ }^{2}$, Ming-Hui Zou ${ }^{1}$ and Ping Song ${ }^{1, * \mathbb{C}}$ \\ 1 Center for Molecular and Translational Medicine, Georgia State University, Atlanta, GA 30302, USA; \\ qzhao@gsu.edu (Q.Z.); mzou@gsu.edu (M.-H.Z.) \\ 2 Department of Science, Redlands Community College, El Reno, OK 73036, USA; \\ kathleen.coughlan@redlandscc.edu \\ * Correspondence: psong@gsu.edu; Tel.: +1-404-413-6636
}

Received: 1 March 2020; Accepted: 15 April 2020; Published: 16 April 2020

\begin{abstract}
Recent evidence indicates that activation of adenosine monophosphate-activated protein kinase (AMPK), a highly conserved sensor and modulator of cellular energy and redox, regulates cell mitosis. However, the underlying molecular mechanisms for AMPK $\alpha$ subunit regulation of chromosome segregation remain poorly understood. This study aimed to ascertain if AMPK $\alpha 1$ deletion contributes to chromosome missegregation by elevating Polo-like kinase 4 (PLK4) expression. Centrosome proteins and aneuploidy were monitored in cultured mouse embryonic fibroblasts (MEFs) isolated from wild type (WT, C57BL/6J) or AMPK $\alpha 1$ homozygous deficient (AMPK $\alpha 1^{-/}$) mice by Western blotting and metaphase chromosome spread. Deletion of AMPK $\alpha 1$, the predominant AMPK $\alpha$ isoform in immortalized MEFs, led to centrosome amplification and chromosome missegregation, as well as the consequent aneuploidy (34-66\%) and micronucleus. Furthermore, AMPK $\alpha 1$ null cells exhibited a significant induction of PLK4. Knockdown of nuclear factor kappa B2/p52 ameliorated the PLK4 elevation in AMPK $\alpha 1$-deleted MEFs. Finally, PLK4 inhibition by Centrinone reversed centrosome amplification of AMPK $\alpha 1$-deleted MEFs. Taken together, our results suggest that $\mathrm{AMPK} \alpha 1$ plays a fundamental role in the maintenance of chromosomal integrity through the control of p52-mediated transcription of PLK4, a trigger of centriole biogenesis.
\end{abstract}

Keywords: AMPK $\alpha 1$; PLK4; p52; centrosome amplification; chromosomal integrity

\section{Introduction}

The accurate segregation of chromosomes during mitosis is required to correctly transmit genetic information to daughter cells. Proper chromosome segregation during mitosis is facilitated by the attachment of mitotic spindle microtubules to the centrosome, the microtubule-organizing organelle of eukaryotic cells [1], and kinetochore, which is assembled on the chromosomal centromere [2]. Abnormal centrosome number is associated with several human diseases, including primary microcephaly [3], renal cystogenesis [4], and cancer [5,6]. Centrosome amplification, with $>2$ centrosomes per cell, sufficiently drives chromosomal missegregation, leading to aneuploidy. This abnormal number of chromosomes in the cell [7] is associated with chromosomal instability (CIN, gain or loss of whole chromosomes) and consequent genomic destabilization [8,9]. However, the underlying mechanisms controlling centrosome over-duplication remain weakly understood.

It was reported that the Polo-like kinases (PLKs, PLK1-5) family [10] and Aurora A/B/C [11] were involved in centrosome biology and cell cycle. Among them, Polo-like kinase 4 (PLK4) is a unique member of the polo family of serine/threonine protein kinases, which is localized to centrioles and plays a well-characterized role in controlling centriole duplication [12,13] and centriole size [14] during the cell cycle. Overexpression of 
PLK4 results in centrosome amplification with excess centrosomes $[15,16]$ and accelerates tumorigenesis in breast and intestinal cancer mouse models [17,18]. However, knockdown or inhibition of PLK4 results in the loss of centrosomes [19]. PLK4 levels peak only transiently during mitosis and are maintained at deficient levels during interphase [20]. PLK4 can be transcriptionally regulated by transcription factor E2F1 [21] or nuclear factor kappa B2 (NF-KB2)-p52 [22]. Kruppel-like factor 14 (KLF14) transcriptionally suppresses PLK4 expression [23]. Additionally, PLK4 is post-translationally controlled. For example, Skp-Cullin-F box (SCF) E3 ubiquitin ligase F-box protein Slimb (SCFSlimb) ubiquitinates and targets PLK4 for proteasomal degradation in Drosophila melanogaster [20,24]. Protein Phosphatase 2A regulatory subunit Twins (PP2ATwins) counteracts PLK4 autophosphorylation, thus stabilizing the mitotic PLK4 [25].

The well-known and conserved energy [26] and redox [27] sensor and regulator, adenosine monophosphate-activated protein kinase (AMPK), also exerts its critical role in cell mitosis [28-30]. A previous study demonstrated that AMPK deletion caused defective mitotic cells with lagging or polyploid chromosomes in a Drosophila model system [31], suggesting that AMPK plays a potential role in chromosomal stability. AMPK was demonstrated to localize on centrosomes [32,33]. Emerging data indicate that AMPK plays a vital role in tumor suppression [34-39]. However, the precise role of the AMPK $\alpha$ subunit and the mechanism by which AMPK might control accurate chromosome segregation during mitosis remain elusive. In the current study, we addressed the involvement of a major AMPK $\alpha$ isoform in fibroblasts, AMPK $\alpha 1$, in chromosome segregation by analyzing centrosome amplification in AMPK $\alpha 1^{-/-}$mouse embryo fibroblasts (MEFs). We present here, for the first time, that AMPK $\alpha 1^{-/-}$MEFs exhibit aneuploidy resulting from centrosome amplification due to p52-mediated PLK4 elevation. These findings identify an unrecognized role for AMPK $\alpha 1$ in chromosome integrity, providing novel insights into the mechanism of tumor suppression mediated by AMPK.

\section{Results}

\subsection{Loss of AMPKa1 Causes Chromosome Instability and Abnormal Nuclei in Mouse Embryonic Fibroblasts (MEFs)}

Given the role of AMPK $\alpha$ in mitosis and DNA damage $[28,30,40]$, we analyzed whether AMPK $\alpha 1$ loss influences chromosome stability. First, we evaluated the ploidy status of proliferative MEFs. As depicted in Figure 1a, AMPK $\alpha 1$ deletion exhibited a higher frequency of aneuploidy ( $40 \%$ of cells) compared to WT cells regardless of the cell cycle stage. To further assess the chromosome instability induced by AMPK $\alpha 1$ deletion, we analyzed chromosome counts from metaphase chromosome spread. As shown in Figure $1 b, c$, a majority of WT MEFs had a $2 n=40$, while AMPK $\alpha 1^{-/-}$MEFs had a wide range and highly variable number of chromosomes, ranging from 32 to 95 chromosomes. Importantly, most cells had between 38 and 50 chromosomes, indicating the loss or gain of a few chromosomes. These results indicate a possible defect in chromosome segregation, leading to chromosome instability in AMPK $\alpha 1^{-/-}$MEFs.

Next, we tested if AMPK $\alpha 1$ affects nuclear structure. As shown in Figure 1d, AMPK $\alpha 1$-deleted MEFs contained various defective mitotic cells with lagging chromosomes (Figure 1d, arrowhead), a flat oval nucleus (Figure 1d, red arrow), and a micronucleus (Figure 1d, white arrow). AMPK $\alpha 1$ deletion in MEFs had about a three-fold increase in chromosome missegregation compared to WT (Figure 1e). These data imply that $\mathrm{AMPK} \alpha 1$ is required for proper chromosome segregation and normal nuclear structure.

\subsection{AMPK $\alpha 1$ Deletion Confers Centrosome Amplification}

Centrosome amplification usually contributes to chromosome instability [8]. Next, we investigated centrosome integrity in AMPK $\alpha 1^{-/-}$MEFs. As shown in Figure 2a-d, AMPK $\alpha 1$ deletion dramatically increased the incidence of centrosome amplification ( $>2$ centrosomes per cell) and spindle multipolarity (green, anti- $\alpha$-tubulin antibody staining) in both prometaphase (Figure 2a,b) and metaphase (Figure 2c,d) of the cell cycle, while WT MEFs had regular centrosome numbers $(=2)$ in the two phases of the cell cycle. 

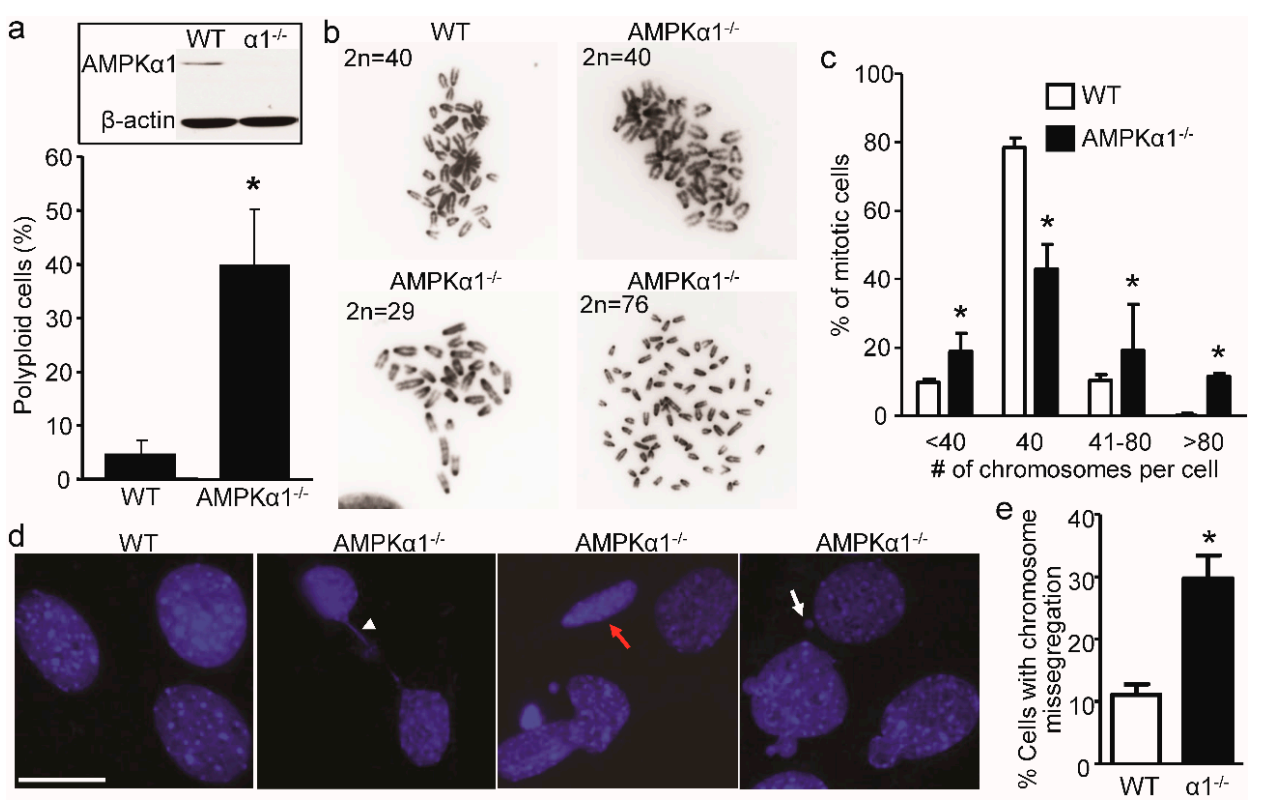

Figure 1. AMPK $\alpha 1$ deletion leads to chromosome instability in Mouse Embryonic Fibroblasts (MEFs). (a) Flow cytometry analysis of DNA content showed an average of about $40 \%$ polyploidy in AMPK $\alpha 1^{-/-}$ MEFs. Data represent the mean \pm S.D. from three separate experiments. ${ }^{*} p<0.01, \mathrm{AMPK} \alpha 1^{-/-}$vs. wild type (WT). Representative Western blot of AMPK $\alpha 1$ was shown as an inset of bar graph; (b) Chromosome instability in AMPK $\alpha 1^{-/-}$MEFs. Representative images of DAPI staining of metaphase chromosome spreads from WT and AMPK $\alpha 1^{-/-}$MEFs are shown; (c) The percentage of MEFs with different chromosome numbers per WT or AMPK $\alpha 1^{-/-}$MEF cell. Data represent the mean \pm S.D. from four separate experiments. * $p<0.01, \mathrm{AMPK} \alpha 1^{-/-}$vs. WT; (d) The abnormal nucleus in AMPK $\alpha 1^{-/-}$MEFs. A lagging chromosome (white arrowhead), a flat oval nucleus (red arrow), and a micronucleus (white arrow) are shown (scale bar $=20 \mu \mathrm{m})$; (e) The bar graph shows the percentages of MEFs with chromosome missegregation. More than 100 cells were counted per group. ${ }^{*} p<0.01, \alpha 1^{-/-}$vs. WT.
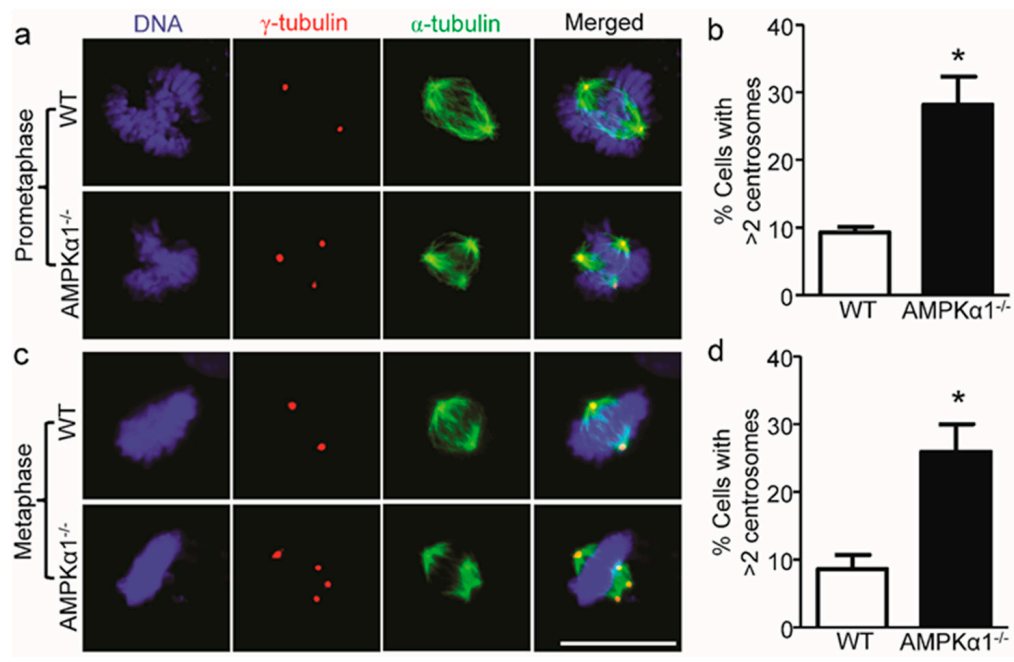

Figure 2. AMPK $\alpha 1$ deletion confers centrosome amplification in MEFs. (a) Representative images of centrosome morphologies of WT and AMPK $\alpha 1^{-/-}$MEFs (scale bar $=20 \mu \mathrm{m}$ ) in the prometaphase of the cell cycle are shown. Centrosomes, spindles, and DNA were co-stained with anti- $\gamma$-tubulin antibody (red), anti- $\alpha$-tubulin antibody (green), and 4.6-diamidino-2-phenylindole (DAPI, blue), respectively, and visualized by fluorescence microscope; (b) Quantification data for the percentage of MEFs containing $>2$ centrosomes are presented. $n=5,{ }^{*} p<0.01$, AMPK $\alpha 1^{-/-}$vs. WT; (c) Representative images of centrosome morphologies of WT and AMPK $\alpha 1^{-/-}$MEFs (scale bar $=20 \mu \mathrm{m}$ ) in the metaphase of the cell cycle are shown; (d) Percentage of cells with $>2$ centrosomes. $\mathrm{n}=5{ }^{*} p<0.01$, AMPK $\alpha 1^{-/-}$vs. WT. 


\subsection{PLK4 Elevates in AMPKa1-Deleted MEFs}

It is well known that PLK4 plays a critical role in centrosome integrity; hence, we inquired whether AMPK $\alpha 1$ regulates PLK4 expression. As shown in Figure 3a, PLK4 protein levels were markedly increased in AMPK $\alpha 1^{-/-}$MEFs compared with WT MEFs (Figure 3a,b). Moreover, PLK4 mRNA levels were significantly upregulated in AMPK $\alpha 1^{-/-}$MEFs compared with WT MEFs (Figure 3c).

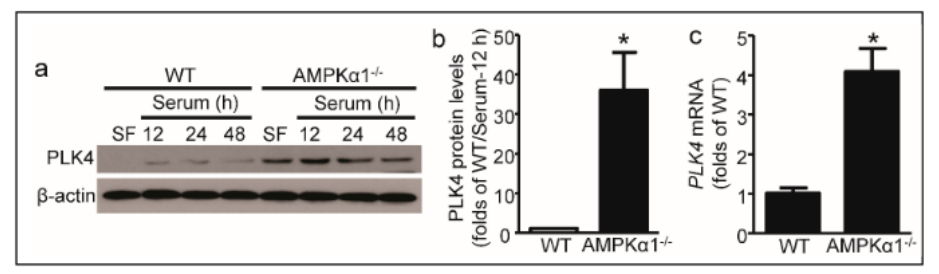

Figure 3. AMPK $\alpha 1$ deletion upregulates PLK4. (a) PLK4 protein levels are elevated in AMPK $\alpha 1^{-/-}$MEFs. $\mathrm{SF}$, serum-free; (b) Quantification data of PLK4 protein levels in WT and AMPK $\alpha 1^{-/-}$MEFs. $n=4,{ }^{*} p<0.01$, AMPK $\alpha 1^{-/-}$vs. WT; (c) PLK4 mRNA elevated in AMPK $\alpha 1^{-/-}$MEFs. $n=3,{ }^{*} p<0.01$, AMPK $\alpha 1^{-/-}$vs. WT.

\subsection{PLK4 Upregulation in AMPK $\alpha 1^{-/-}$MEFs Is p52-Mediated}

Next, we wanted to know the underlying mechanism for PLK4 elevation in AMPK $\alpha 1^{-/-}$MEFs. Since it was reported that AMPK $\alpha 1$ deletion upregulates nuclear factor-kappa B2/p52 [35], we tested if p52 mediates PLK4 upregulation in AMPK $\alpha 1^{-/-}$MEFs. As depicted in Figure 4a, p52 knockdown by specific siRNA dramatically blocked the AMPK $\alpha 1^{-/}$-upregulated PLK4 mRNA. Furthermore, p52 knockdown profoundly decreased PLK4 protein levels in AMPK $\alpha 1^{-/-}$MEFs compared with control siRNA (Figure 4b,c). Finally, p52 knockdown normalized the elevated centrosome number (Figure 4d) and decreased the percentage of cells with supernumerary centrosomes in AMPK $\alpha 1$-deleted MEFs (Figure 4e).

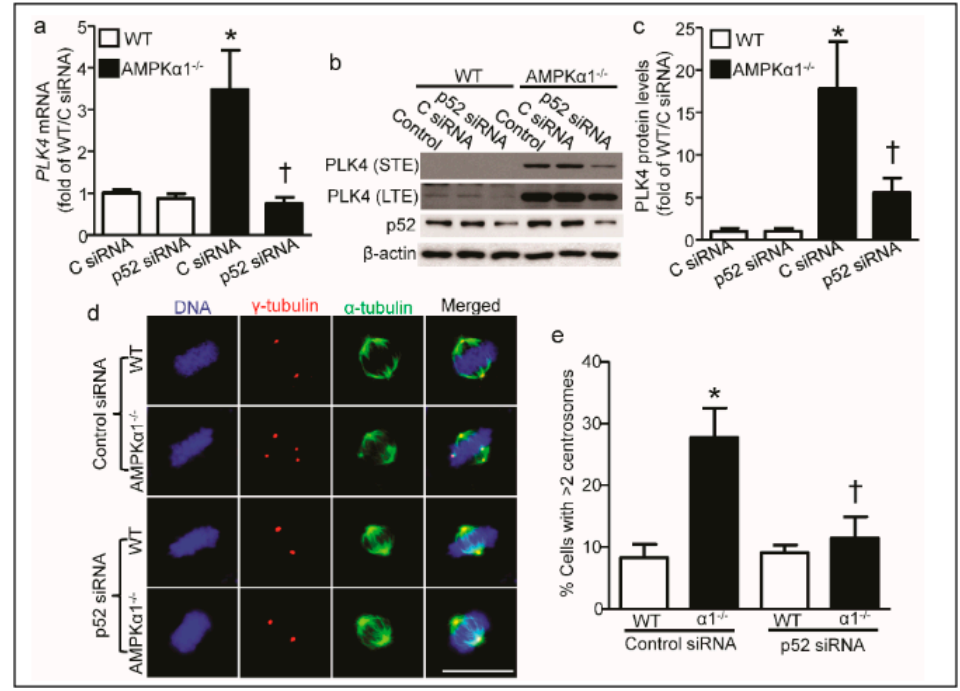

Figure 4. PLK4 elevation is p52-mediated. (a) p52 knockdown blocked the PLK4 mRNA upregulation in AMPK $\alpha 1^{-/-}$MEFs. $n=3,{ }^{*} p<0.01$, vs. C siRNA/WT; $+p<0.01$, vs. C siRNA/AMPK $\alpha 1^{-/-}$; (b) Representative Western blotting showed 552 siRNA decreased the PLK4 protein elevated in AMPK $\alpha 1^{-/-}$MEFs. STE: short-term exposure; LTE: long-term exposure; (c) Quantification data of PLK4 protein levels for (b); $n=4,{ }^{*} p<0.01$, vs. C siRNA/WT; $+p<0.01$, vs. C siRNA/AMPK $\alpha 1^{-1-}$; (d) MEFs were treated with $\mathrm{p} 52$ siRNA or control siRNA for $72 \mathrm{~h}$ before the start of the experiment. Cells were treated with $20 \mathrm{ng} / \mathrm{mL}$ nocodazole for 4 hours to depolymerize microtubules. Centrosomes, spindles, and DNA were co-stained with anti- $\gamma$-tubulin antibody (red), anti- $\alpha$-tubulin antibody (green), and 4.6-diamidino-2-phenylindole (DAPI, blue), respectively, and visualized by fluorescence microscope (scale bar $=20 \mu \mathrm{m}$ ). Representative images are shown; (e) Quantification data represent the mean \pm S.D. from three separate experiments. ${ }^{*} p<0.01$, vs. WT/control siRNA; $+p<0.01$, vs. AMPK $\alpha 1^{-/-} /$control siRNA. C siRNA: control siRNA. 


\subsection{PLK4 Inhibition Ameliorates Centrosome Amplification in AMPK $\alpha 1^{-/-}$MEFs}

Next, we investigated whether PLK4 mediates abnormal centrosome amplification in AMPK $\alpha 1^{-/-}$ MEFs. As shown in Figure 5a, Centrinone, a potent and specific small molecular PLK4 inhibitor [19], effectively normalized the elevation of centrosome number in AMPK $\alpha 1^{-/-}$MEFs, but it had no effect on centrosome number in WT MEFs. Furthermore, Centrinone treatment markedly inhibited the hyper-proliferation of AMPK $\alpha 1^{-/-}$MEFs, whereas it did not alter WT MEFs proliferation performed with cellular passaging assay (Figure $5 b$ ).
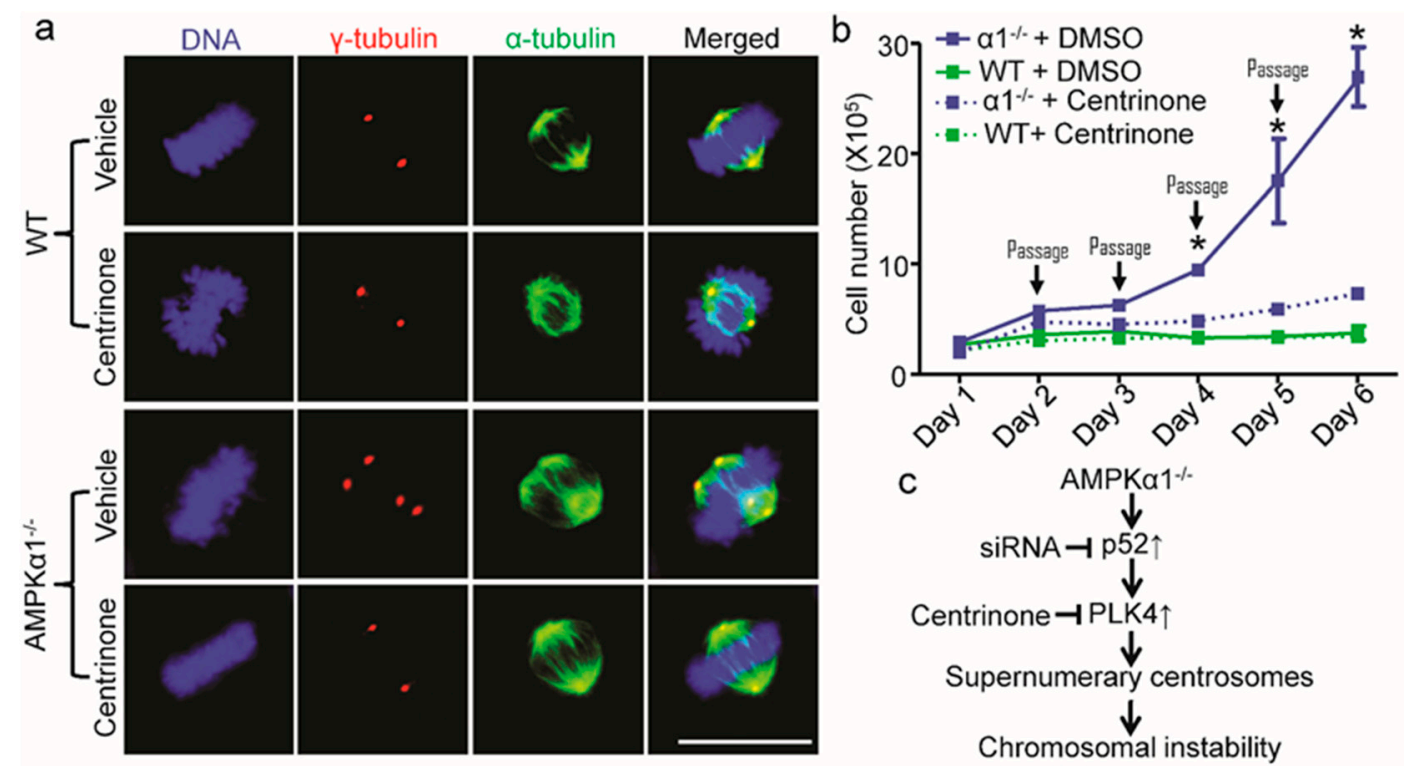

Figure 5. PLK4 inhibition reverses centrosome amplification and cell hyperproliferation in AMPK $\alpha 1$ deleted MEFs. (a) PLK4 inhibition by Centrinone blocked centrosome amplification in $\mathrm{AMPK} \alpha 1^{-/-}$ MEFs. MEFs were treated with Centrinone $(125 \mathrm{nM})$ or vehicle (DMSO) for $16 \mathrm{~h}$. The cells were treated with nocodazole $(20 \mathrm{ng} / \mathrm{mL})$ for 4 hours to depolymerize the microtubules. Then, centrosomes, spindles, and DNA were co-stained with anti- $\gamma$-tubulin antibody (red), anti- $\alpha$-tubulin antibody (green), and 4.6-diamidino-2-phenylindole (DAPI, blue), respectively, and visualized by fluorescence microscope (scale bar $=20 \mu \mathrm{m}$ ); (b) PLK4 inhibition restrained cellular hyperproliferation in AMPK $\alpha 1^{-/-}$MEFs. MEF cells were seeded into $10-\mathrm{cm}$ tissue culture dishes at $1 \times 10^{5}$ cells/dish. Centrinone was added at $125 \mathrm{nM}$. Every day, cells were harvested, counted using a Bio-Rad cell counter, and re-seeded into new dishes. Quantification data represent the mean \pm S.D. from three separate experiments. ${ }^{*} p<0.01$, vs. $\alpha 1^{-/-}+$Centrinone; (c) A scheme illustrating the role of p52-PLK4 in AMPK $\alpha 1$ deletion-mediated centrosome amplification. P52 transcriptionally regulates PLK4, which contributes to centrosome amplification and the consequent chromosome instability.

\section{Discussion}

In the present study, we demonstrated that AMPK $\alpha 1$ deletion mediates aneuploidy in MEFs. The mechanism underlying this process is due to the elevated p52-mediated PLK4 upregulation (Figure 5c). These findings suggest that AMPK $\alpha 1$ is a pivotal regulator for the high fidelity of chromosome segregation.

Accumulating evidence indicates that AMPK controls the cell cycle $[41,42]$ and mitosis $[28,30]$ via distinct mechanisms. AMPK may control the fidelity of chromosome segregation. For example, the constitutive expression of AMPK-related kinase, NUAK1, leads to gross aneuploidies and the consequent cellular senescence in human fibroblast, WI-38 [43]. Knockdown of both AMPK $\alpha 1$ and AMPK $\alpha 2$ decreases the number and length of astral microtubules per spindle pole in human cancer cells, H1299 and HeLa [30]. Banko et al. reported that AMPK $\alpha 2$ phosphorylates protein phosphatase 1 regulatory subunit 12C (PPP1R12C) and p21-activated protein kinase (PAK2), which mediates the serine 19 phosphorylation of myosin regulatory light chain (pMRLC-S19) [28]. Thus, AMPK regulates actin 
cortex-astral microtubule attachments via pMRLC-S19 to control proper mitotic spindle orientation, which mediates accurate chromosome segregation [30]. In addition, the effect of AMPK $\alpha 1$ deletion on ploidy and mitotic defects were investigated in the context of liver regeneration. In contrast to the current results in MEFs, no difference in ploidy or mitotic defects (e.g., chromosomal misalignments) were observed in the AMPK $\alpha 1^{-/-}$regenerative liver tissue section [44]. Of note, an interesting difference between MEFs and hepatocytes is the high expression of the AMPK $\alpha 2$ catalytic subunit in the liver but not in MEFs [44], which may support functional redundancy and explain these discrepancies.

Although PLK1 inhibitor GW843682X blocks AMPK $\alpha$ activation during the cell cycle [33], it is unknown whether AMPK $\alpha$ is inactivated by PLK1 inhibition directly or due to the blockage of cell cytokinesis, because cell mitosis consumes energy and activates AMPK $[40,45]$. Here, we present that AMPK $\alpha 1$ deletion up-regulates the mRNA and protein levels of PLK4 dramatically, which plays a critical regulatory role in the duplication of centrioles and is involved in the correct segregation of sister chromatids [46] and standard nuclear structure [16]. Thus, PLK4 induction and defective centrosome in AMPK $\alpha 1$-deleted MEFs may be responsible for the lagging chromosomes and chromatin bridges [46], which might work as the primary cause of micronuclei (MN) formation and the subsequent aneuploidy [16,47]. Although p52 contributes to PLK4 upregulation, the downregulated p21 in AMPK $\alpha 1$-deleted MEFs [40] may also mediate the PLK4 elevation [48]. It is noteworthy that the induction of PLK4 mRNA level in AMPK $\alpha 1$-deleted MEFs was almost entirely restored by p52 siRNA (Figure 4a), while the PLK4 protein level in AMPK $\alpha 1$-deleted MEFs was partially reversed by p52 siRNA (Figure 4c), indicating that post-translational regulation may be involved in PLK4 protein induction in AMPK $\alpha 1$-deleted MEFs. Thus, it is warranted the investigation of the effect of AMPK $\alpha 1$ on PLK4 protein stability and the underlying mechanisms.

Extra centrosomes in AMPK $\alpha 1$-deleted MEFs would result in aneuploidy and chromosome segregation errors that contribute to the increased DNA damage [40,49]. Incorrect chromosome separation would lead to cellular apoptosis or hyperproliferation. p52 knockdown by specific shRNA inhibits the enhanced colony formation of AMPK $\alpha 1$-deleted MEFs [35], suggesting that p52 upregulation plays a critical role in the hyperproliferation of AMPK $\alpha 1$-deleted MEFs. Additionally, AMPK $\alpha 1$ deletion-mediated chromosome missegregation-caused cellular hyperproliferation may be due to p21 reduction, which is consistent with p21 knockout and contributes to the growth of PLK4-overexpressing cells [50].

Loss of AMPK $\alpha 1$ culminates in centrosome amplification and spontaneous chromosomal abnormalitiesderanged genome instability in fibroblasts. Recent studies from Li et al. have uncovered a previously unrecognized function of AMPK in protecting the replication fork structure upon replication stress to ensure genome stability [51]. As AMPK is an essential modulator of cell metabolism and redox balance, it will be interesting to examine whether AMPK $\alpha 1$ regulates centrosome integrity-associated genomic fidelity, in part via modulating cellular redox balance. Interestingly, AICAR (5-aminoimidazole-4-carboxamide ribonucleoside), a well-known AMPK activator [52], selectively induces the apoptosis of aneuploid (trisomic) MEFs and human cancer cell lines [53]. Since aneuploidy is a hallmark of cancer, AMPK may be a promising and selective drug target for aneuploidy-related cancer therapy.

In conclusion, our studies revealed an important role for AMPK $\alpha 1$ in cell biology and connected two hallmarks of human cancer: chromosomal instability and hyperproliferation. Given the importance of AMPK in the cell cycle, these findings hold profound implications for understanding the molecular mechanisms, by which AMPK acts as a potential tumor suppressor.

\section{Materials and Methods}

\subsection{Materials and Reagents}

The following antibodies were purchased from Cell Signaling Technology (Beverly, MA, USA): rabbit anti-PLK4 (3258), rabbit anti-p52 (4882), rabbit anti- $\alpha$-tubulin (2125), anti-rabbit IgG-HRP (7074), and anti-mouse IgG-HRP (7076). Mouse anti-PLK1 antibody (ab17057) was from Abcam (Cambridge, MA, USA). Mouse anti- $\beta$-actin antibody (sc-47778) was obtained from Santa Cruz Biotechnology (Santa 
Cruz, CA, USA). Mouse anti- $\gamma$-tubulin antibody (MA119421) was from Thermo Scientific (Rockford, IL, USA). NFkB p52 siRNA (m) (sc-36043) and control siRNA (sc-37007) were from Santa Cruz Biotechnology. Other chemicals and organic solvents of the highest available grade were obtained from Sigma-Aldrich (St. Louis, MO, USA). AMPK $\alpha 1^{-/-}$mice were described elsewhere [54,55]. Mice were handled following animal protocols approved by the Institutional Animal Care and Use Committee of the University of Oklahoma Health Sciences Center (Oklahoma City, OK, USA).

\subsection{Cell Culture and Transfection}

Mouse embryonic fibroblasts (MEFs) were isolated from AMPK $\alpha 1^{-/-}$and WT mouse embryos at 13.5 days post-coitus, and cells were spontaneously immortalized by the 3T3 protocol, as described previously [56,57]. A 13.5-day mouse fetus was decapitated, and the liver and heart were removed. The remaining part of the fetus was washed by sterile PBS, thoroughly minced, and trypsinized $(0.25 \%$ trypsin-EDTA, Cat. No. 25200-072, Thermo Fisher Scientific, Grand Island, NY, USA). The dissociated cells were resuspended. To immortalize MEFs, cells were passaged serially according to the 3T3 protocol $\left(3 \times 10^{5}\right.$ cells were plated in a $60 \mathrm{~mm}$ tissue culture dish every three days) until the proliferation rate in the culture stabilized. Cells were then cultured for an additional 15 passages (to about passage 35) and, at that point, were considered immortalized and used for experiments. MEFs were cultured in Dulbecco's modified Eagle medium (DMEM, Invitrogen, Carlsbad, CA, USA) supplemented with 10\% $v / v$ FBS, L-Glutamine (2 mM) (Lonza, Walkersville, MD, USA), penicillin (100 U/mL), and streptomycin $(100 \mu \mathrm{g} / \mathrm{mL})$ (Life Technologies, Grand Island, NY, USA). For cell synchronization in the G0/G1 phase, MEFs were starved with a serum-free medium for $48 \mathrm{~h}$ and then re-incubated with complete medium for the indicated times.

\subsection{Indirect Immunofluorescence Analysis}

Cells were grown to exponential phase on poly-L-lysine-coated glass coverslips and then were fixed with $4 \%$ paraformaldehyde in PBS, permeabilized with $0.1 \%$ Triton X-100 in PBS or image-IT Fix (Cat. No. R37602, Invitrogen, Carlsbad, CA, USA), and blocked with $3 \%$ bovine serum albumin (BSA) in PBS. Primary antibodies used were rabbit anti- $\alpha$-tubulin (1:100 $v / v)$ and mouse anti- $\gamma$-tubulin (1:100 $v / v$ ). DNA was stained with antifade reagent with 4',6-diamidino-2-phenylindole (DAPI) (Invitrogen, Carlsbad, CA, USA). For indirect immunofluorescence, Alexa Fluor®488 or 555 were used for the detection of protein. Confocal microscopy was performed using a Zeiss 710 confocal microscope (Jena, Germany) with a 100× oil immersion lens. Image editing was performed in Adobe Systems Incorporated (San Jose, CA, USA).

\subsection{RNA Extraction, cDNA Synthesis, and Real Time PCR}

Total mRNA was isolated and purified using the RNeasy mini kit from Qiagen (Valencia, CA, USA) according to the manufacturer's instructions. cDNA was synthesized from isolated mRNA using the iScript cDNA synthesis kit (Bio-Rad Laboratories, Hercules, CA, USA), as described previously [55] and following the manufacturer's instructions. Real-time PCR was performed on a CFX96 Touch ${ }^{\mathrm{TM}}$ Real-Time PCR Detection System (Bio-Rad, Hercules, CA, USA) with SYBR Green PCR Master Mix (ThermoFisher Scientific, Waltham, MA, USA) and one $\mu \mathrm{l}$ of the first-strand cDNA as a template with specific primers for PLK4 (5'-GAGCGTGAATAGTGCCGCTTTC-3' 5' $^{\prime}$-TGAACCCACACAGC TCCGCTAG-3'). The levels of gene expression were determined relative to that of GAPDH ( $5^{\prime}$-AAGG TCATCCCAGAGCTGAA-3' ${ }^{\prime}$, ${ }^{\prime}$-CTGCTTCACCACCTTCTTGA-3').

\subsection{Metaphase Chromosome Spreads}

MEFs growing in an exponential phase were incubated with $0.01 \mu \mathrm{g} / \mathrm{ml}$ colcemid (Calbiochem, Gibbstown, NJ, USA) for $3 \mathrm{~h}$. Cells were harvested by trypsinization, swollen in $75 \mathrm{mM} \mathrm{KCl}$ at $37^{\circ} \mathrm{C}$ for $20 \mathrm{~min}$, fixed with 3:1 methanol/acetic acid $(v / v)$, and dropped onto clean, ice-cold glass microscope slides [58]. The slides were air-dried and stained with DAPI for $10 \mathrm{~min}$. Chromosome numbers were 
evaluated using a microscope (BX53TF; Olympus, Tokyo, Japan) and a digital camera (DP80; Olympus, Tokyo, Japan) under a $100 \times / 1.4$ oil objective. At least 50 metaphases were analyzed per sample.

\subsection{Flow Cytometry Analysis}

Exponentially growing cells were collected by trypsin digestion and fixed in ice-cold $80 \%$ ethanol in PBS for at least $2 \mathrm{~h}$. Cells were stained with $50 \mu \mathrm{g} / \mathrm{mL}$ propidium iodide (PI) in the presence of $10 \mu \mathrm{g} / \mathrm{mL}$ DNase-free RNase. Cell cycle profiles were determined by FACSDiVa (Becton-Dickinson Bioscience, San Jose, CA, USA), and data were analyzed using FCS Express V3 software (Los Angeles, CA, USA). For the analysis of aneuploidy, a Multicycle plug-in was used.

\subsection{Protein Extraction and Western Blotting}

Whole-cell extracts were prepared by employing cell lysis buffer (9803) from Cell Signaling Technology with protease and phosphatase inhibitor cocktails I and II (Cat. \# BP-479 and BP-480, Boston BioProducts, MA, USA). Protein samples (30-60 $\mu \mathrm{g})$ were loaded and separated by SDS-PAGE and transferred onto nitrocellulose membranes. The membrane was blocked by $5 \%$ nonfat powdered milk in TBST (50 mM Tris, pH 7.5, $150 \mathrm{mM} \mathrm{NaCl}, 0.1 \%$ Tween 20) for $30 \mathrm{~min}$ and then probed with different antibodies in $4 \%$ powdered milk in TBST, as previously described [59]. The membrane was washed extensively with TBST, and then incubated with the appropriate horseradish peroxidase (HRP)-linked secondary antibodies (Cell Signaling Technology, Beverly, MA, USA). Signals were visualized with an enhanced chemiluminescence detection system (GE Healthcare, Pittsburgh, PA, USA) and quantified by densitometry. Equal loading of protein was verified by immunoblotting with the anti- $\beta$-actin antibody.

\subsection{Passaging Assays}

Cellular passaging assays were performed as previously described [19]. Briefly, MEF cells were seeded into $10 \mathrm{~cm}$ tissue culture dishes at $1 \times 10^{5}$ cells/dish. Centrinone was added at $125 \mathrm{nM}$. Total cells were harvested, counted using a Bio-Rad cell counter, and re-seeded daily into new dishes.

\subsection{Statistical Analysis}

Data were presented as mean \pm S.D. Differences between multiple means were evaluated by two-tailed Student's $t$-test or analysis of variance with post hoc Bonferroni corrections. A $p$ value $<$ 0.05 was considered statistically significant.

\section{Conclusions}

AMPK $\alpha 1$ maintains chromosomal integrity through the control of p52-mediated transcription of PLK4, a trigger of centriole biogenesis.

Author Contributions: Conceptualization, P.S.; Methodology, Q.Z. and K.A.C.; Validation, Q.Z.; Formal analysis, Q.Z.; Investigation, Q.Z. and K.A.C.; Writing—original draft preparation, P.S.; Writing—review and editing, P.S. and K.A.C.; Funding acquisition, P.S. and M.-H.Z. All authors have read and agreed to the published version of the manuscript.

Funding: This research was funded in part by the following agency: National Heart, Lung, and Blood Institute (HL140954). M.-H. Zou is an eminent scholar of the Georgia Research Alliance.

Conflicts of Interest: The authors declare no conflict of interest.

\section{Abbreviations}

AMPK adenosine monophosphate-activated protein kinase

CIN chromosomal instability

MEFs mouse embryonic fibroblasts

PLK4 Polo-like kinase 4 


\section{References}

1. Nigg, E.A.; Holland, A.J. Once and only once: Mechanisms of centriole duplication and their deregulation in disease. Nat. Rev. Mol. Cell Biol. 2018, 19, 297-312. [CrossRef]

2. Westhorpe, F.G.; Straight, A.F. Functions of the centromere and kinetochore in chromosome segregation. Curr. Opin. Cell Biol. 2013, 25, 334-340. [CrossRef]

3. Thornton, G.K.; Woods, C.G. Primary microcephaly: Do all roads lead to rome? Trends Genet. 2009, 25, 501-510. [CrossRef]

4. Dionne, L.K.; Shim, K.; Hoshi, M.; Cheng, T.; Wang, J.; Marthiens, V.; Knoten, A.; Basto, R.; Jain, S.; Mahjoub, M.R. Centrosome amplification disrupts renal development and causes cystogenesis. J. Cell Biol. 2018, 217, 2485-2501. [CrossRef]

5. Zyss, D.; Gergely, F. Centrosome function in cancer: Guilty or innocent? Trends Cell Biol. 2009, 19, $334-346$. [CrossRef] [PubMed]

6. Chan, J.Y. A clinical overview of centrosome amplification in human cancers. Int. J. Biol. Sci. 2011, 7, 1122-1144. [CrossRef] [PubMed]

7. Torres, E.M.; Williams, B.R.; Amon, A. Aneuploidy: Cells losing their balance. Genetics 2008, 179, 737-746. [CrossRef] [PubMed]

8. $\quad$ Lingle, W.L.; Barrett, S.L.; Negron, V.C.; D'Assoro, A.B.; Boeneman, K.; Liu, W.; Whitehead, C.M.; Reynolds, C.; Salisbury, J.L. Centrosome amplification drives chromosomal instability in breast tumor development. Proc. Natl. Acad. Sci. USA 2002, 99, 1978-1983. [CrossRef]

9. Passerini, V.; Ozeri-Galai, E.; de Pagter, M.S.; Donnelly, N.; Schmalbrock, S.; Kloosterman, W.P.; Kerem, B.; Storchova, Z. The presence of extra chromosomes leads to genomic instability. Nat. Commun. 2016, 7, 10754. [CrossRef]

10. de Cárcer, G.; Manning, G.; Malumbres, M. From plk1 to plk5. Cell Cycle 2011, 10, 2255-2262. [CrossRef]

11. Li, S.; Deng, Z.; Fu, J.; Xu, C.; Xin, G.; Wu, Z.; Luo, J.; Wang, G.; Zhang, S.; Zhang, B.; et al. Spatial compartmentalization specializes the function of aurora a and aurora b. J. Biol. Chem. 2015, 290, 17546-17558. [CrossRef]

12. Habedanck, R.; Stierhof, Y.D.; Wilkinson, C.J.; Nigg, E.A. The polo kinase plk4 functions in centriole duplication. Nat. Cell Biol. 2005, 7, 1140-1146. [CrossRef]

13. Fournier, M.; Orpinell, M.; Grauffel, C.; Scheer, E.; Garnier, J.M.; Ye, T.; Chavant, V.; Joint, M.; Esashi, F.; Dejaegere, A.; et al. Kat2a/kat2b-targeted acetylome reveals a role for plk4 acetylation in preventing centrosome amplification. Nat. Commun. 2016, 7, 13227. [CrossRef]

14. Aydogan, M.G.; Wainman, A.; Saurya, S.; Steinacker, T.L.; Caballe, A.; Novak, Z.A.; Baumbach, J.; Muschalik, N.; Raff, J.W. A homeostatic clock sets daughter centriole size in flies. J. Cell Biol. 2018, 217, 1233-1248. [CrossRef]

15. Coelho, P.A.; Bury, L.; Shahbazi, M.N.; Liakath-Ali, K.; Tate, P.H.; Wormald, S.; Hindley, C.J.; Huch, M.; Archer, J.; Skarnes, W.C.; et al. Over-expression of plk4 induces centrosome amplification, loss of primary cilia and associated tissue hyperplasia in the mouse. Open Biol. 2015, 5, 150209. [CrossRef]

16. Ganem, N.J.; Godinho, S.A.; Pellman, D. A mechanism linking extra centrosomes to chromosomal instability. Nature 2009, 460, 278-282. [CrossRef]

17. Sercin, O.; Larsimont, J.C.; Karambelas, A.E.; Marthiens, V.; Moers, V.; Boeckx, B.; Le Mercier, M.; Lambrechts, D.; Basto, R.; Blanpain, C. Transient plk4 overexpression accelerates tumorigenesis in p53-deficient epidermis. Nat. Cell Biol. 2016, 18, 100-110. [CrossRef]

18. Levine, M.S.; Bakker, B.; Boeckx, B.; Moyett, J.; Lu, J.; Vitre, B.; Spierings, D.C.; Lansdorp, P.M.; Cleveland, D.W.; Lambrechts, D.; et al. Centrosome amplification is sufficient to promote spontaneous tumorigenesis in mammals. Dev. Cell 2017, 40, 313-322. [CrossRef]

19. Wong, Y.L.; Anzola, J.V.; Davis, R.L.; Yoon, M.; Motamedi, A.; Kroll, A.; Seo, C.P.; Hsia, J.E.; Kim, S.K.; Mitchell, J.W.; et al. Cell biology. Reversible centriole depletion with an inhibitor of polo-like kinase 4. Science 2015, 348, 1155-1160. [CrossRef]

20. Rogers, G.C.; Rusan, N.M.; Roberts, D.M.; Peifer, M.; Rogers, S.L. The scf slimb ubiquitin ligase regulates plk4/sak levels to block centriole reduplication. J. Cell Biol. 2009, 184, 225-239. [CrossRef] 
21. Tategu, M.; Nakagawa, H.; Sasaki, K.; Yamauchi, R.; Sekimachi, S.; Suita, Y.; Watanabe, N.; Yoshid, K. Transcriptional regulation of human polo-like kinases and early mitotic inhibitor. J. Genet. Genom. 2008, 35, 215-224. [CrossRef]

22. Ledoux, A.C.; Sellier, H.; Gillies, K.; Iannetti, A.; James, J.; Perkins, N.D. Nfkappab regulates expression of polo-like kinase 4. Cell Cycle 2013, 12, 3052-3062. [CrossRef]

23. Fan, G.; Sun, L.; Shan, P.; Zhang, X.; Huan, J.; Zhang, X.; Li, D.; Wang, T.; Wei, T.; Zhang, X.; et al. Loss of klf14 triggers centrosome amplification and tumorigenesis. Nat. Commun. 2015, 6, 8450. [CrossRef] [PubMed]

24. Cunha-Ferreira, I.; Rodrigues-Martins, A.; Bento, I.; Riparbelli, M.; Zhang, W.; Laue, E.; Callaini, G.; Glover, D.M.; Bettencourt-Dias, M. The scf/slimb ubiquitin ligase limits centrosome amplification through degradation of sak/plk4. Curr. Biol. 2009, 19, 43-49. [CrossRef]

25. Brownlee, C.W.; Klebba, J.E.; Buster, D.W.; Rogers, G.C. The protein phosphatase 2a regulatory subunit twins stabilizes plk4 to induce centriole amplification. J. Cell Biol. 2011, 195, 231-243. [CrossRef]

26. Hardie, D.G.; Ross, F.A.; Hawley, S.A. Ampk: A nutrient and energy sensor that maintains energy homeostasis. Nat. Rev. Mol. Cell Biol. 2012, 13, 251-262. [CrossRef] [PubMed]

27. Song, P.; Zou, M.H. Regulation of nad(p)h oxidases by ampk in cardiovascular systems. Free Radic. Biol. Med. 2012, 52, 1607-1619. [CrossRef] [PubMed]

28. Banko, M.R.; Allen, J.J.; Schaffer, B.E.; Wilker, E.W.; Tsou, P.; White, J.L.; Villen, J.; Wang, B.; Kim, S.R.; Sakamoto, K.; et al. Chemical genetic screen for ampkalpha2 substrates uncovers a network of proteins involved in mitosis. Mol. Cell 2011, 44, 878-892. [CrossRef]

29. Vazquez-Martin, A.; Lopez-Bonet, E.; Oliveras-Ferraros, C.; Perez-Martinez, M.C.; Bernado, L.; Menendez, J.A. Mitotic kinase dynamics of the active form of ampk (phospho-ampkalphathr172) in human cancer cells. Cell Cycle 2009, 8, 788-791. [CrossRef]

30. Thaiparambil, J.T.; Eggers, C.M.; Marcus, A.I. Ampk regulates mitotic spindle orientation through phosphorylation of myosin regulatory light chain. Mol. Cell Biol. 2012, 32, 3203-3217. [CrossRef]

31. Lee, J.H.; Koh, H.; Kim, M.; Kim, Y.; Lee, S.Y.; Karess, R.E.; Lee, S.H.; Shong, M.; Kim, J.M.; Kim, J.; et al. Energy-dependent regulation of cell structure by amp-activated protein kinase. Nature 2007, 447, 1017-1020. [CrossRef]

32. Vazquez-Martin, A.; Oliveras-Ferraros, C.; Menendez, J.A. The active form of the metabolic sensor: Amp-activated protein kinase (ampk) directly binds the mitotic apparatus and travels from centrosomes to the spindle midzone during mitosis and cytokinesis. Cell Cycle 2009, 8, 2385-2398. [CrossRef]

33. Vazquez-Martin, A.; Oliveras-Ferraros, C.; Cufi, S.; Menendez, J.A. Polo-like kinase 1 regulates activation of amp-activated protein kinase (ampk) at the mitotic apparatus. Cell Cycle 2011, 10, 1295-1302. [CrossRef] [PubMed]

34. Zhou, J.; Huang, W.; Tao, R.; Ibaragi, S.; Lan, F.; Ido, Y.; Wu, X.; Alekseyev, Y.O.; Lenburg, M.E.; Hu, G.F.; et al. Inactivation of ampk alters gene expression and promotes growth of prostate cancer cells. Oncogene 2009, 28, 1993-2002. [CrossRef] [PubMed]

35. Zhou, Y.; Xu, H.; Ding, Y.; Lu, Q.; Zou, M.H.; Song, P. Ampkalpha1 deletion in fibroblasts promotes tumorigenesis in athymic nude mice by p52-mediated elevation of erythropoietin and cdk2. Oncotarget 2016, 7, 53654-53667. [PubMed]

36. Faubert, B.; Boily, G.; Izreig, S.; Griss, T.; Samborska, B.; Dong, Z.; Dupuy, F.; Chambers, C.; Fuerth, B.J.; Viollet, B.; et al. Ampk is a negative regulator of the warburg effect and suppresses tumor growth in vivo. Cell Metab. 2013, 17, 113-124. [CrossRef] [PubMed]

37. Pineda, C.T.; Ramanathan, S.; Fon Tacer, K.; Weon, J.L.; Potts, M.B.; Ou, Y.H.; White, M.A.; Potts, P.R. Degradation of ampk by a cancer-specific ubiquitin ligase. Cell 2015, 160, 715-728. [CrossRef] [PubMed]

38. Vila, I.K.; Yao, Y.; Kim, G.; Xia, W.; Kim, H.; Kim, S.J.; Park, M.K.; Hwang, J.P.; Gonzalez-Billalabeitia, E.; Hung, M.C.; et al. A ube2o-ampkalpha2 axis that promotes tumor initiation and progression offers opportunities for therapy. Cancer Cell 2017, 31, 208-224. [CrossRef]

39. Wu, D.; Hu, D.; Chen, H.; Shi, G.; Fetahu, I.S.; Wu, F.; Rabidou, K.; Fang, R.; Tan, L.; Xu, S.; et al. Glucose-regulated phosphorylation of tet 2 by ampk reveals a pathway linking diabetes to cancer. Nature 2018, 559, 637-641. [CrossRef] 
40. Xu, H.; Zhou, Y.; Coughlan, K.A.; Ding, Y.; Wang, S.; Wu, Y.; Song, P.; Zou, M.H. Ampkalpha1 deficiency promotes cellular proliferation and DNA damage via p21 reduction in mouse embryonic fibroblasts. Biochim. Biophys. Acta 2015, 1853, 65-73. [CrossRef]

41. Igata, M.; Motoshima, H.; Tsuruzoe, K.; Kojima, K.; Matsumura, T.; Kondo, T.; Taguchi, T.; Nakamaru, K.; Yano, M.; Kukidome, D.; et al. Adenosine monophosphate-activated protein kinase suppresses vascular smooth muscle cell proliferation through the inhibition of cell cycle progression. Circ. Res. 2005, 97, 837-844. [CrossRef] [PubMed]

42. Song, P.; Wang, S.; He, C.; Liang, B.; Viollet, B.; Zou, M.H. Ampkalpha2 deletion exacerbates neointima formation by upregulating skp2 in vascular smooth muscle cells. Circ. Res. 2011, 109, 1230-1239. [CrossRef] [PubMed]

43. Humbert, N.; Navaratnam, N.; Augert, A.; Da Costa, M.; Martien, S.; Wang, J.; Martinez, D.; Abbadie, C.; Carling, D.; de Launoit, Y.; et al. Regulation of ploidy and senescence by the ampk-related kinase nuak1. EMBO J. 2010, 29, 376-386. [CrossRef] [PubMed]

44. Merlen, G.; Gentric, G.; Celton-Morizur, S.; Foretz, M.; Guidotti, J.E.; Fauveau, V.; Leclerc, J.; Viollet, B.; Desdouets, C. Ampk $\alpha 1$ controls hepatocyte proliferation independently of energy balance by regulating cyclin a2 expression. J. Hepatol. 2014, 60, 152-159. [CrossRef] [PubMed]

45. Mao, L.; Li, N.; Guo, Y.; Xu, X.; Gao, L.; Xu, Y.; Zhou, L.; Liu, W. Ampk phosphorylates gbf1 for mitotic golgi disassembly. J. Cell Sci. 2013, 126, 1498-1505. [CrossRef]

46. Gopalakrishnan, S.; Sullivan, B.A.; Trazzi, S.; Della Valle, G.; Robertson, K.D. Dnmt3b interacts with constitutive centromere protein cenp-c to modulate DNA methylation and the histone code at centromeric regions. Hum. Mol. Genet. 2009, 18, 3178-3193. [CrossRef]

47. Hinchcliffe, E.H.; Day, C.A.; Karanjeet, K.B.; Fadness, S.; Langfald, A.; Vaughan, K.T.; Dong, Z. Chromosome missegregation during anaphase triggers p53 cell cycle arrest through histone h3.3 ser31 phosphorylation. Nat. Cell Biol. 2016, 18, 668-675. [CrossRef]

48. Fischer, M.; Quaas, M.; Steiner, L.; Engeland, K. The p53-p21-dream-cde/chr pathway regulates g2/m cell cycle genes. Nucleic Acids Res. 2016, 44, 164-174. [CrossRef]

49. Janssen, A.; van der Burg, M.; Szuhai, K.; Kops, G.J.; Medema, R.H. Chromosome segregation errors as a cause of DNA damage and structural chromosome aberrations. Science 2011, 333, 1895-1898. [CrossRef] [PubMed]

50. Lambrus, B.G.; Daggubati, V.; Uetake, Y.; Scott, P.M.; Clutario, K.M.; Sluder, G.; Holland, A.J. A usp2853bp1-p53-p21 signaling axis arrests growth after centrosome loss or prolonged mitosis. J. Cell Biol. 2016, 214, 143-153. [CrossRef]

51. Li, S.; Lavagnino, Z.; Lemacon, D.; Kong, L.; Ustione, A.; Ng, X.; Zhang, Y.; Wang, Y.; Zheng, B.; Piwnica-Worms, H.; et al. $\mathrm{Ca}(2+)$-stimulated ampk-dependent phosphorylation of exo1 protects stressed replication forks from aberrant resection. Mol. Cell 2019, 74, 1123-1137.e1126. [CrossRef] [PubMed]

52. Wang, S.; Xu, J.; Song, P.; Viollet, B.; Zou, M.H. In vivo activation of amp-activated protein kinase attenuates diabetes-enhanced degradation of gtp cyclohydrolase i. Diabetes 2009, 58, 1893-1901. [CrossRef] [PubMed]

53. Tang, Y.C.; Williams, B.R.; Siegel, J.J.; Amon, A. Identification of aneuploidy-selective antiproliferation compounds. Cell 2011, 144, 499-512. [CrossRef]

54. Jorgensen, S.B.; Viollet, B.; Andreelli, F.; Frosig, C.; Birk, J.B.; Schjerling, P.; Vaulont, S.; Richter, E.A.; Wojtaszewski, J.F. Knockout of the alpha2 but not alpha1 5'-amp-activated protein kinase isoform abolishes 5-aminoimidazole-4-carboxamide-1-beta-4-ribofuranosidebut not contraction-induced glucose uptake in skeletal muscle. J. Biol. Chem. 2004, 279, 1070-1079. [CrossRef] [PubMed]

55. Cai, Z.; Ding, Y.; Zhang, M.; Lu, Q.; Wu, S.; Zhu, H.; Song, P.; Zou, M.H. Ablation of adenosine monophosphate-activated protein kinase alpha1 in vascular smooth muscle cells promotes diet-induced atherosclerotic calcification in vivo. Circ. Res. 2016, 119, 422-433. [CrossRef] [PubMed]

56. Wang, S.; Song, P.; Zou, M.H. Inhibition of amp-activated protein kinase alpha (ampkalpha) by doxorubicin accentuates genotoxic stress and cell death in mouse embryonic fibroblasts and cardiomyocytes: Role of p53 and sirt1. J. Biol Chem. 2012, 287, 8001-8012. [CrossRef] [PubMed]

57. Todaro, G.J.; Green, H. Quantitative studies of the growth of mouse embryo cells in culture and their development into established lines. J. Cell Biol. 1963, 17, 299-313. [CrossRef] 
58. Deng, W.; Tsao, S.W.; Lucas, J.N.; Leung, C.S.; Cheung, A.L. A new method for improving metaphase chromosome spreading. Cytometry A 2003, 51, 46-51. [CrossRef]

59. Ding, Y.; Han, Y.; Lu, Q.; An, J.; Zhu, H.; Xie, Z.; Song, P.; Zou, M.H. Peroxynitrite-mediated sirt (sirtuin)-1 inactivation contributes to nicotine-induced arterial stiffness in mice. Arterioscler. Thromb. Vasc. Biol. 2019, 39, 1419-1431. [CrossRef] 